\title{
Neumonía severa fatal por Pneumocistis jirovecii e Influenza A en un paciente con dermatomiositis amiopática y síndrome antisintetasa
}

\author{
Fatal severe pneumonia caused by Pneumocystis \\ jirovecii and influenza $A$ in a patient with amyopathic \\ dermatomyositis and antisynthetase syndrome
}

\author{
Liliana Fernández MD.(1); Manuel Alejandro Pérez MD.(2); Pablo Andrés Moncada MD.(3); \\ LUZ FERNANDA SUA, MD., PHD. ${ }^{(4)}$
}

\begin{abstract}
Resumen
Tradicionalmente, la neumonía por Pneumocistis jirovecii se ha relacionado con pacientes en estado de inmunodeficiencia marcada, principalmente con infección por virus de inmunodeficiencia humana (VIH). Sin embargo, dada la presencia de ciertas condiciones clínicas como el cáncer, los síndromes linfoproliferativos, los trasplantes (en especial los de órgano sólido), las enfermedades autoinmunes y el uso de medicamentos inmunosupresores para el manejo de estas condiciones, las infecciones por Pneumocistis jirovecii son cada vez más frecuentes a pesar de la profilaxis, que en los países en desarrollo no se cumple a cabalidad en todos los pacientes, lo cual genera mayor morbimortalidad en poblaciones vulnerables. A esto se suma el que las coinfecciones en pacientes inmunosuprimidos son una situación común que empeora su pronóstico.
\end{abstract}

En esta oportunidad se presenta el caso de un paciente con infección por Pneumocistis jirovecii e Influenza A, quien tenía de base diagnóstico de dermatomiositis amiopática y síndrome antisintetasa en tratamiento con esteroides e inmunosupresores.

Palabras clave: neumonía, Pneumocistis jirovecii, influenza A, dermatomiositis.

\footnotetext{
${ }^{(1)}$ Medicina Interna, Neumología, Neumología Intervencionista, Línea del Investigación Biomédica en Tórax, Fundación Valle del Lili. Profesora Clínica Asociada, Facultad de Ciencias de la Salud, Universidad Icesi. Cali-Colombia.

(2)Medicina Interna, Facultad de Ciencias de la Salud, Universidad Icesi. Cali-Colombia.

${ }^{(3)}$ Medicina Interna, Infectología, Fundación Valle del Lili. Profesor Clínico Asistente, Facultad de Ciencias de la Salud, Universidad Icesi. Cali-Colombia.

${ }^{(4)}$ Anatomía Patológica y Patología Clínica, Departamento de Patología y Medicina de Laboratorio, Patología pulmonar. Ciencias Biomédicas. Línea de investigación Biomédica en Tórax, Fundación Valle del Lili. Profesora Clínica Asistente, Facultad de Ciencias de la Salud, Universidad Icesi. Cali, Colombia.

Correspondencia: Liliana Fernández T., correos electrónicos: 1fernandez@fcvl.org, lilianafernandeztrujillo@gmail.com

Recibido: 25/08/15. Aceptado: 30/08/15.
} 


\section{Caso}

Paciente de 32 años de edad con cuadro clínico de 2 años de evolución de poliartritis simétrica que comprometía articulaciones de mano, muñecas, codos, hombros, cuello, rodillas, tobillos y pies, en manejo y seguimiento por Reumatología. Con base en la presentación clínica, los hallazgos de laboratorio y la biopsia cutánea tenía diagnóstico de dermatomiositis amiopática, síndrome antisintetasa con compromiso pulmonar manifestado como neumonía intersticial difusa y hepatitis autoinmune. Recibía de manera crónica prednisolona $15 \mathrm{mg} /$ día y cloroquina con evolución irregular y en los últimos meses, con marcada actividad inflamatoria, incluyendo elevación persistente de las transaminasas, anemia y eritrosedimentación aumentada. Se agregó, por tanto, ciclofosfamida y se aumentó la dosis de esteroides, pero no se obtuvo una respuesta significativa, razón por la que se decidió incluir ciclosporina A en el esquema de tratamiento.

Consultó a su servicio médico de síntomas respiratorios de dos semanas de evolución: tos seca, sin expectoración o hemoptisis, disnea leve, fiebre $\left(38-39^{\circ} \mathrm{C}\right)$, escalofríos, cefalea, dolor retro-ocular y decaimiento. Fue hospitalizado para estudio. El cuadro clínico se interpretó como posible infección respiratoria versus exacerbación de la enfermedad pulmonar intersticial asociada a la enfermedad reumática de base. Se inició esquema de antibióticos y pulsos de esteroides endovenosos, con lo que se obtuvo mejoría parcial y se dio de alta con control ambulatorio. Dos semanas después, consultó nuevamente por reaparición de los síntomas: tos seca, disnea, en esta oportunidad más severa, escalofrío y fiebre, y fue remitido a nuestra institución. Al ingreso se encontró paciente en regular estado general, TA 90/60 mm Hg, FC 110 lpm, FR 24 por minuto, saturación de oxígeno $75 \%\left(\mathrm{FiO}_{2} 0,21\right)$ y $90 \%$ $\left(\mathrm{FiO}_{2} 0,32\right)$. En el examen físico se observó: disnea en reposo con habla entrecortada, mucosas semisecas, no cianosis, no ictericia, eritema en heliotropo, no ingurgitación yugular, tirajes supraclaviculares, no masas en cuello, ruidos respiratorios disminuidos en ambas bases pulmonares con estertores finos, corazón rítmico taquicárdico sin soplos frote o galope, abdomen sin viceromegalias, extremidades con edema grado I pápulas de Gottron en manos, sistema nervioso central sin déficit neurológico ni lateralización. Los exámenes de laboratorio mostraron: fracción de complemento $\mathrm{C} 3$ y $\mathrm{C} 4$ dentro de parámetros normales, bilirrubinas normales, AST 116, ALT 77, LDH 450, función renal conservada, PCR 9,27; recuento celular con 7.660 leucocitos (neutrófilos 7.250, linfocitos 200), Hb 11,5 y plaquetas 189.000. La radiografía de tórax mostró infiltrados intersticiales bilaterales de predominio periférico (figura 1). Se realizó escanografía de tórax en la que se encontraron infiltrados mixtos con engrosamiento septal y áreas extensas de infiltrados en vidrio esmerilado (figuras 2 y 3 ).

Teniendo en cuenta el contexto clínico del paciente, los medicamentos de base, la evolución de su enfermedad y el antecedente de una hospitalización reciente sin mejoría completa, se inició terapia antibiótica con cefepime, vancomicina, moxifloxacino y oseltamivir por la posibilidad de una infección en un huésped inmunosuprimido, previa toma de diferentes cultivos. Evolucionó rápidamente a falla respiratoria hipoxémica con progresión severa de los infiltrados pulmonares, que no se estabilizó con la ventilación

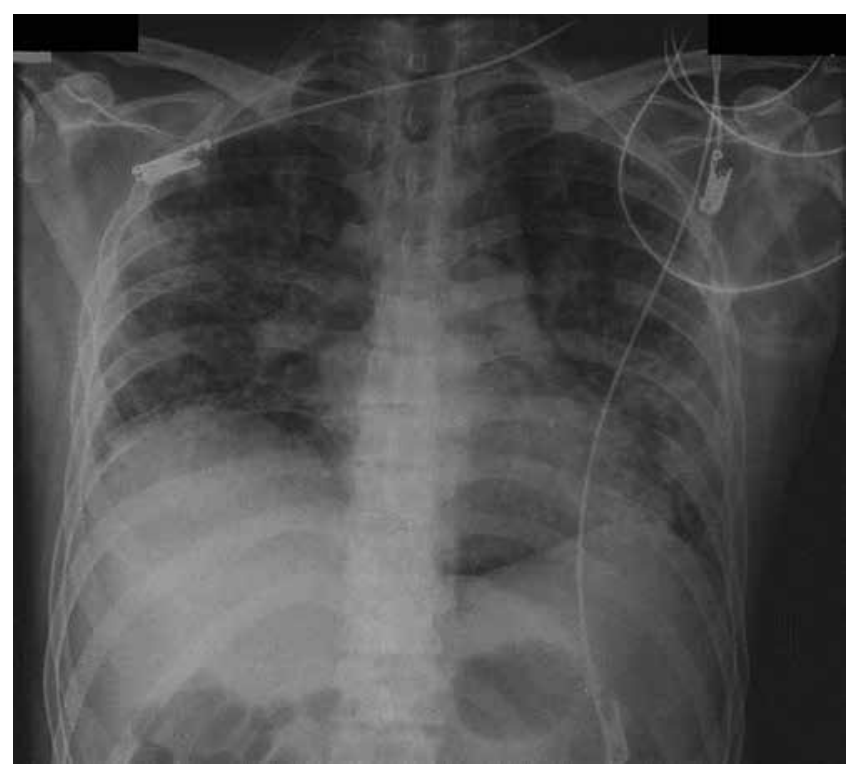

Figura 1. Aspecto de la radiografía de tórax con infiltrados intersticiales bilaterales periféricos. 

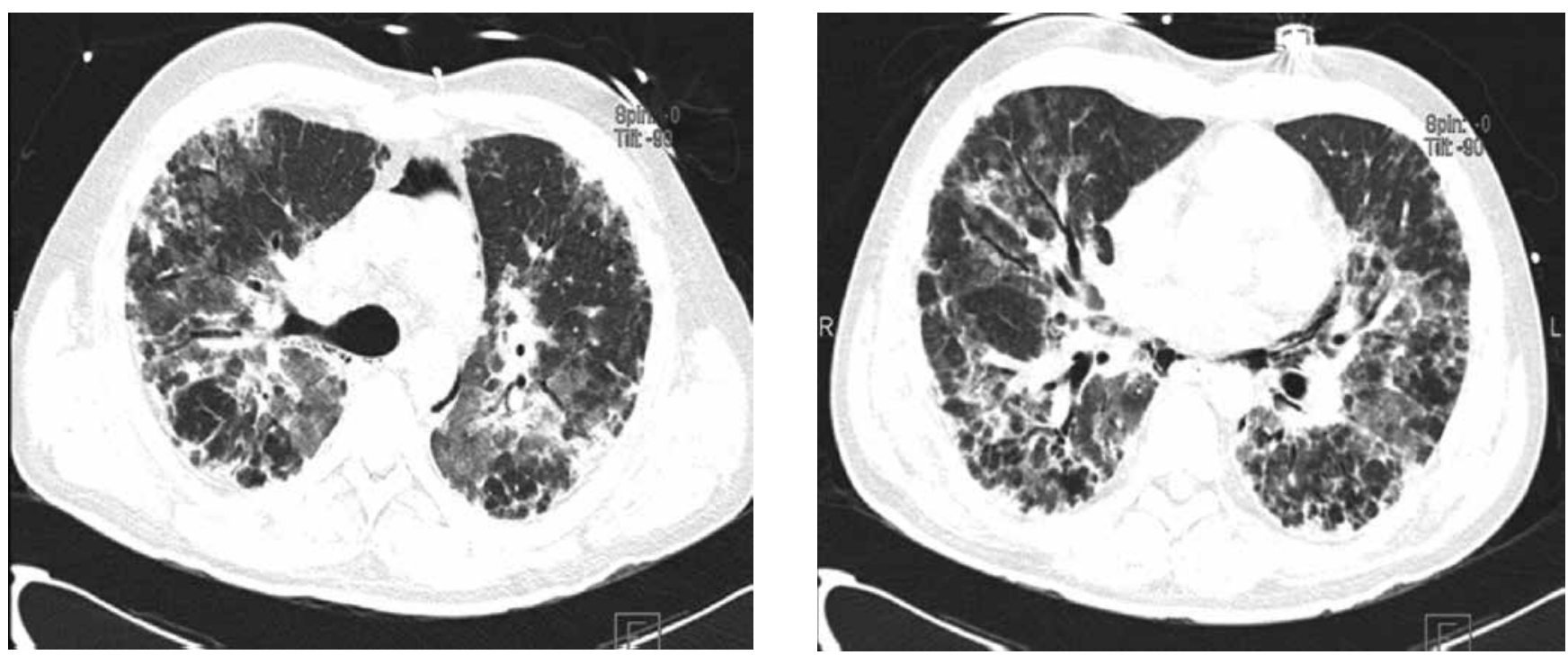

Figuras 2 y 3 . TAC de tórax en las que se aprecia infiltrado intersticial con engrosamiento septal difuso y áreas extensas de infiltrados en vidrio esmerilado.

mecánica no invasiva, por lo cual se procedió a realizar intubación orotraqueal y soporte con ventilación mecánica invasiva. Se realizó una fibrobroncoscopia que reveló endobronquitis generalizada, con secreciones espumosas no purulentas en moderada cantidad. En el lavado broncoalveolar se encontró predominio de linfocitos en la coloración de Papanicolaou, en tanto que en la coloración de metenamina de plata se observaron formas quísticas de Pneumocistis jirovecci (figuras 4 y 5). Adicionalmente, se reportaron hemocultivos negativos, cultivos de lavado broncoalveolar

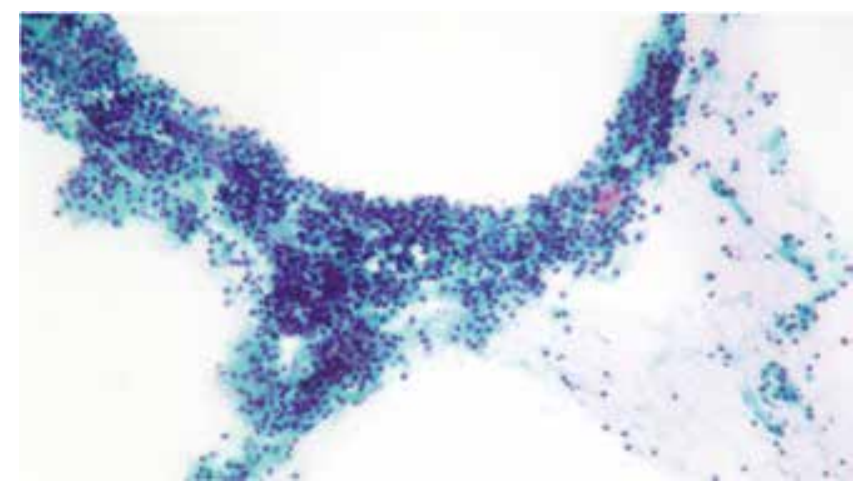

Figura 4. Muestra de lavado broncoalveolar. Citología en base líquida. Coloración de Papanicolaou (10x) donde se aprecia fondo inflamatorio de predominio linfoide. para bacterias negativos, directos para hongos y micobacterias negativos, GeneXpert negativo para tuberculosis, y reporte de panel para virus respiratorios positivo para Influenza A.

Con estos resultados se adicionó al manejo trimeto$\mathrm{prim} / \mathrm{sulfametoxazol}$, con el cual inicialmente hubo mejoría clínica, estabilización de los parámetros hemodinámicos $\mathrm{y}$ ventilatorios, pero posteriormente se presentó deterioro progresivo, fiebre persistente, hipotensión refractaria pese a manejo vasopresor y muerte.

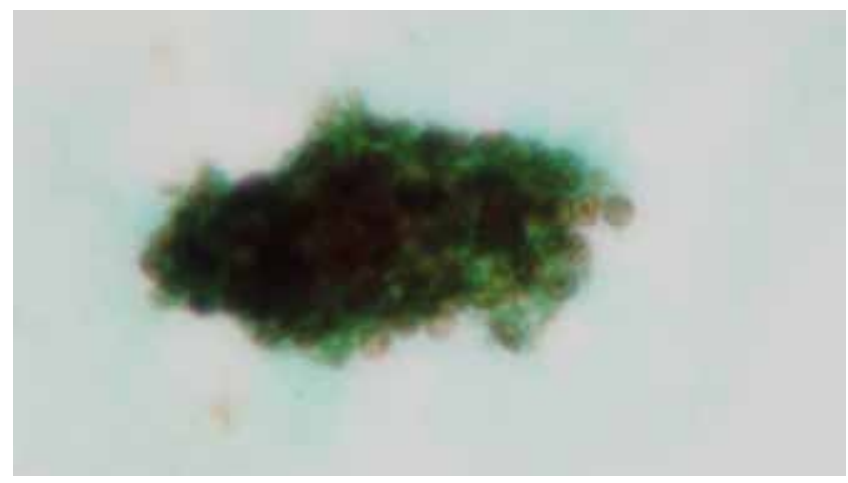

Figura 5. Muestra de lavado broncoalveolar. Citología en base líquida. Coloración de metenamina plata (10x) donde se aprecian formas quísticas de Pneumocystis jirovecii. 


\section{Discusión}

Las miopatías inflamatorias idiopáticas son un grupo de enfermedades del tejido conectivo que incluyen la polimiositis, la dermatomiositis y la dermatomiositis amiopática $(1,2)$; cada una de ellas se asocia con un grado variable de inflamación muscular y de compromiso sistémico incluyendo piel, articulaciones y pulmón. En este último caso, el compromiso es en la forma de enfermedad pulmonar intersticial y va desde subclínica a fulminante (3-5). La prevalencia del compromiso pulmonar en los pacientes con miositis oscila entre un 20 a un $78 \%$ y su presencia aumenta la morbilidad y la mortalidad (6). El riesgo de presentar enfermedad pulmonar intersticial se asocia con autoanticuerpos específicos para miositis, incluyendo anti-PM/Scl, anti-tRNAaminocil sintetasa y anti-MDA-5 (7).

Por su parte, la dermatomiositis amiopática se caracteriza por presentar las manifestaciones cutáneas de la enfermedad pero sin evidencia clínica ni serológica de miositis $(8,9)$. Se estima que representa el $20 \%$ de todos los casos de dermatomiositis (10). El comienzo usualmente ocurre en la edad adulta temprana, es más común en mujeres, el compromiso pulmonar es más severo y está presente en más del $50 \%$ de los pacientes. La manifestación radiológica más común son los infiltrados retículo-nodulares difusos con parches bilaterales de vidrio esmerilado, mientras que en los pacientes con enfermedad pulmonar intersticial asociada a dermatomiositis es muy probable que haya anti-Jo-1, anticuerpo típicamente ausente en aquellos con dermatomiositis amiopática (11).

Por otra parte, los anticuerpos antisintetasa están dirigidos a una de las 20 enzimas requeridas para acoplar cada tRNA con un aminoácido; hasta ahora se han identificado 8 anticuerpos antisintetasa $(12,13)$. La presencia de uno de ellos combinada con enfermedad pulmonar intersticial y una de las miopatías inflamatorias, se conoce como síndrome antisintetasa, que incluye además otros rasgos clínicos como artritis, manos de mecánico, fenómeno de Raynaud y fiebre; el compromiso pulmonar en este caso es del 67 al 100\% dependiendo del tipo de anticuerpos y de los métodos diagnósticos utilizados (14).
El tratamiento de primera línea en la enfermedad intersticial asociada a cualquier variante de las miopatías y el síndrome antisintetasa son altas dosis de esteroides además de inmunosupresión con múltiples agentes incluyendo ciclofosfamida, azatioprina, micofenolato mofetil, ciclosporina, tacrolimus, rituximab e inmunoglobulina intravenosa; sin embargo una proporción importante de pacientes con enfermedad aguda o subaguda pulmonar no mejora a pesar de la terapia múltiple (15-17).

En el caso expuesto el paciente tenía diagnóstico de dermatomiositis amiopática y síndrome antisintetasa. Fue sometido a tratamiento agresivo, considerando síntomas como progresión de la enfermedad pulmonar intersticial, no solo con esteroides a altas dosis sino con varios tipos de inmunosupresores. En esta situación se plantea siempre la posibilidad de infecciones oportunistas únicas o múltiples como causa del cuadro clínico o como consecuencia del tratamiento de la enfermedad de base.

El Pneumocistis jirovecii, anteriormente conocido como Pneumocystis carinii f. sp. hominis, continúa siendo uno de los patógenos oportunistas más comunes que afecta a individuos con síndrome de inmunodeficiencia adquirida (SIDA) y pacientes con inmunosupresión debida a otras causas como cáncer, malignidad hematológica, trasplante de médula ósea y órgano sólido, rechazo de órganos, tratamiento para ciertas condiciones inflamatorias particularmente enfermedades reumatológicas, inmunodeficiencias primarias y malnutrición severa. Estos datos son corroborados por Matsumura et al. (18) en una de las series más grandes hasta ahora publicadas de infección por Pneumocistis en individuos no-VIH, en la cual las enfermedades inflamatorias fueron la condición de base más frecuente para desarrollar la enfermedad, situación en la cual a menudo es fatal (19). Además, describen que en los pacientes VIH la introducción de la terapia antirretroviral disminuyó significativamente la incidencia de PCP (infección por Pneumocistis jirovecii).

Este microorganismo previamente considerado un protozoo, es un hongo atípico, extracelular, unicelular, con marcado estenoxenismo, y no cultivable in vitro; es precisamente esta última característica, el principal obstáculo para el conocimiento de su 
biología y su estudio genético. El modo de transmisión de un individuo a otro no ha sido del todo esclarecido y la forma infectiva del hongo aún no se identifica. Se propone un modelo de transmisión similar al del Mycobacterium tuberculosis; se considera que los niños, quienes se contaminan rápidamente después del nacimiento con PCP, se convierten en un gran reservorio del microorganismo. Se plantea la vía aérea como vehículo, considerando que las formas tróficas, con un tamaño de 2 a $4 \mu \mathrm{m}$, similares al bacilo tuberculoso (1-3 $\mu \mathrm{m})$, pueden ser expectoradas por el paciente infectado y mediante microgotas ser adquiridas por los sujetos susceptibles en quienes eventualmente causarían enfermedad o en los sujetos inmunocompetentes en quienes se comportarían como colonizadores no patógenos (20). En general, se encuentra restringido a los pulmones, aunque se ha demostrado su presencia en otras regiones del cuerpo.

El diagnóstico de PCP se debe considerar en pacientes con factores de riesgo quienes acuden con cuadro neumónico e infiltrados difusos, especialmente en aquellos sometidos a terapia inmunosupresora combinada como en este caso, esteroides y ciclofosfamida, y no han recibido profilaxis. De igual forma, el diagnóstico requiere la documentación del microorganismo en especímenes respiratorios, muestras de lavado broncoalveolar o esputo inducido, en las que se identifican las formas tróficas con Gram-Weigert, Wright-Giemsa o Papanicolaou modificado y la pared celular de los quistes con gomori, metenamina de plata o azul de toluidine. Hoy, la técnica más usada en el mundo es la de anticuerpos fluorescentes directos usando un anticuerpo monoclonal conjugado con fluoresceína, que puede visualizar las formas tróficas y los quistes (21).

Otra alternativa para el diagnóstico especialmente en pacientes en quienes no se pueda realizar una broncoscopia, es el (1-3)- $\beta$-D-glucan sérico, un componente de la pared celular de todos los hongos incluido el Pneumocistis, que se identifica en suero y se usa como tamizaje para infecciones micóticas invasivas como Cándida y Aspergillus que también es útil para el diagnóstico de PCP, con sensibilidad del $96 \%$ y especificidad del $87 \%$ (22). Puede, así mismo, tener un rol en la evaluación diagnóstica especialmente para descartar la enfermedad con valor predictivo negativo alto (23).

Debido a la poca cantidad de quistes en el lavado brocoalveolar, el diagnóstico de PCP se convierte en un reto usando solo los métodos convencionales de microscopía en los pacientes inmunosuprimidos noVIH y en los VIH que reciben terapia antirretroviral. En general, el lavado broncoalveolar tiene una positividad diagnóstica entre 70 y $92 \%$; por lo tanto, en la actualidad se están desarrollado varios métodos de reacción en cadena de la polimerasa PCR cuantitativa en tiempo real, que si bien es cierto, solo indican si hay material genético del Pneumocistis en la muestra que puede no estar generando enfermedad, serán de utilidad en poblaciones de riesgo para diferenciar una infección activa de una colonización, haciendo uso además de los datos clínicos y de los factores de riesgo. Hasta el momento no están disponibles comercialmente pero se están haciendo estudios de validación que en un futuro cercano darán la posibilidad de utilizar alguna de estas pruebas diagnósticas $(24,25)$.

Otro aspecto al cual conviene hacer referencia, es que tanto la presentación clínica, como el desenlace de la enfermedad, son diferentes en el paciente VIH positivo y en el paciente no VIH (26-28). En el primer grupo la enfermedad tiene un curso clínico más lento, con una mortalidad inferior al $10 \%(29,30)$. Sin embargo, en el segundo grupo de pacientes la enfermedad progresa rápidamente y es más severa (31). Esta severidad y mayor mortalidad (en los pacientes no VIH con PCP) puede explicarse porque no se empieza el tratamiento de manera oportuna, debido a un bajo índice de sospecha y por la respuesta inmunológica alterada del huésped que también desempeña un papel importante. Dicha respuesta involucra interacciones entre linfocitos T CD4 y CD8, neutrófilos, macrófagos alveolares y mediadores que facilitan la resolución de la enfermedad. Las células T CD4 proliferan en respuesta a la infección y generan IFN- $\gamma$, que induce el reclutamiento de macrófagos; también se libera IL-8 de las células epiteliales y macrófagos, y se une fuertemente a neutrófilos reclutados, hecho que ayuda al aclaramiento 
del microorganismo, pero durante este proceso los mediadores inflamatorios también generan proteasas y radicales libres de oxígeno que ocasionan lesión pulmonar. La neumonía por PCP severa se caracteriza por inflamación pulmonar con abundante presencia de neutrófilos, que conlleva daño alveolar difuso, alteración en el intercambio gaseoso y falla respiratoria (32). En pacientes no VIH se han identificado niveles mayores de IL-8, comparado con pacientes VIH (33).

La relación entre peor desenlace y retraso en el tratamiento aún no se ha establecido claramente, dada la falta de reportes de casos y poca evidencia disponible. Yusuke et al. demostraron que cuando el inicio de la terapia se retrasa por más de siete días, aumenta la necesidad de soporte ventilatorio invasivo; respecto a la mortalidad no tuvieron diferencias entre intubación y no intubación. Sin embargo, en este estudio el grupo de pacientes con soporte ventilatorio invasivo, tuvo mayor riesgo de desarrollar complicaciones, tales como neumonía asociada al ventilador (34).

Existe debate si los pacientes tienen una colonización previa por el Pneumocistis o presentan infección de novo. Se ha reportado que en pacientes VIH las tasas de colonización pueden ser hasta de un $69 \%$ (35), además se ha demostrado la colonización en individuos no $\mathrm{VIH}$, al igual que se han identificado en biopsias de pulmón post-mortem de individuos sanos, lo que indica que la colonización es altamente prevalente en la población general (36).

Aproximadamente, 1 a $2 \%$ de los pacientes con enfermedades reumatológicas desarrollan PCP, por lo general en el momento de la mayor intensidad de la terapia inmunosupresora con esteroides y un segundo medicamento; no es claro si hay una predisposición a desarrollar PCP en ciertas enfermedades reumáticas, algunos piensan que el riesgo es mayor en polimiositis y dermatomiositis, en tanto que es más bajo en lupus eritematoso sistémico con la misma intensidad de inmunosupresión (37).

Teniendo en cuenta los síntomas inespecíficos, que se pueden confundir fácilmente con otras infecciones respiratorias, la población susceptible cada vez mayor por el uso de terapias inmunosupresoras, la falta de métodos diagnósticos eficaces y oportunos y el desenlace clínico más severo y en muchos casos fatal, es de vital importancia indicar la profilaxis antibiótica en los casos que aplique y siempre considerar al Pneumocistis dentro del diagnóstico diferencial en este grupo de pacientes y una vez sospechado y tomadas las muestras pertinentes, empezar el tratamiento específico.

En el caso descrito se encontró además evidencia de infección por influenza A los cual complicó aun más el cuadro del paciente, quien tenía antecedente de enfermedad autoinmune, estaba en tratamiento con medicamentos inmunosupresores y cursaba con infección por Pneumocistis. El impacto de las condiciones médicas de base en los pacientes con influenza se ha explorado extensamente en la literatura; entidades tales como la diabetes o el asma inciden en el curso y la gravedad de la infección (38). En un estudio reciente se describe que en sitios donde hay alta prevalencia de coinfecciones o comorbilidades, éstas se convierten en un factor de riesgo para tener infección por influenza más severa, casi fatal, como es el caso de ciertas poblaciones del África donde hay alta prevalencia de tuberculosis, VIH, hemoglobinopatías y malnutrición, además de brotes de enfermedades infecciosas como dengue, malaria, sarampión, meningococo y $\mathrm{PCP}$, que pueden coexistir con influenza (39).

La influenza es una infección respiratoria aguda causada por los virus influenza A y B que ocurre en brotes y en forma epidémica en todo el mundo, presenta signos y síntomas de compromiso del tracto respiratorio superior e inferior junto con fiebre, cefalea, mialgias y debilidad; es aguda pero autolimitada en la población general, en cuyo caso se denomina influenza no complicada, pero en poblaciones de alto riesgo se asocia con mayor morbilidad y mortalidad, y se conoce como influenza complicada (40).

Las personas infectadas poseen gran cantidad de virus de la influenza en las secreciones respiratorias; por tanto se trasmite fácilmente a través de estornudos o tos, por medio de gotas o partículas grandes mayores de 5 micras que no permanecen suspendidas en el aire por mucho tiempo, de modo que se 
necesita contacto estrecho con el individuo infectado. El periodo de incubación es de uno a cuatro días, hasta dos semanas (41).

Comienza de manera abrupta con fiebre, cefalea, mialgias y malestar, y posteriormente aparecen manifestaciones del tracto respiratorio como tos no productiva, odinofagia y rinorrea. Tiene un amplio espectro de presentación desde leve como el resfriado, hasta compromiso severo del estado general con síntomas respiratorios prominentes.

La complicación más importante de la influenza es la neumonía, la cual ocurre con mayor frecuencia en pacientes con enfermedades crónicas y clasificados como de alto riesgo, tales como mayores de 65 años, con enfermedades pulmonares crónicas, cardiovasculares, renales, hepáticas, hematológicas, metabólicas, neurológicas, neuromusculares, sometidos a inmunosupresión, VIH, cáncer, malignidad hematológica, embarazadas, obesos o pacientes institucionalizados como ocurrió con el paciente del caso clínico (42).

Puede presentarse como neumonía viral primaria, cuando los virus comprometen directamente el pulmón produciendo neumonía severa, en cuyo caso los síntomas persisten e incrementan de manera progresiva con fiebre alta, disnea y falla respiratoria. Es la complicación más severa pero es poco común.

La neumonía bacteriana secundaria es otra complicación importante de la influenza y contribuye sustancialmente a la morbilidad y mortalidad, especialmente en pacientes mayores de 65 años. Se manifiesta como exacerbación de la fiebre y de los síntomas respiratorios después de una mejoría inicial en el curso de la influenza aguda (43). Las demás complicaciones de la influenza pueden ser cardiacas, o manifestarse como miositis, rabdomiólisis, complicaciones del sistema nervioso central y síndrome de shock tóxico.

Las pruebas de diagnóstico rápido para la influenza disponibles son inmunoensayos que pueden identificar la presencia de antígenos nucleoprotéicos virales de la influenza A y B en muestras respiratorias que exponen el resultado de forma cuantitativa (positivo/negativo). Los resultados se pueden obtener en treinta minutos pero la sensibilidad de la prueba es limitada y los resultados negativos deben interpretarse con cautela debido a la posibilidad de falsos negativos, especialmente durante el pico de actividad de la influenza en una comunidad. Existen, además, pruebas para la confirmación de una infección por el virus con reacción en cadena de la polimerasa con transcriptasa reversa (RT-PCR) que tienen mayor sensibilidad (44). Igualmente, en vista de que las infecciones virales constituyen un diagnóstico diferencial importante en los pacientes con comorbilidades asociadas, existen ya en el mercado diferentes pruebas que detectan PCR múltiples de 17 virus y al menos tres bacterias que requieren pocos minutos de procesamiento en instrumentación; en el paciente del caso se utilizó una de ellas y se detectó la presencia de influenza A asociada (45).

En conclusión, se describió el caso de un paciente no VIH severamente inmunosuprimido, con enfermedad autoinmune con compromiso pulmonar intersticial y coinfección fatal por Pneumocistis jirovecii e influenza A y se hizo revisión de la literatura.

\section{Bibliografía}

1. Bohan A, Peter JB. Polymyositis and dermatomyositis (first of two parts). N Engl J Med. 1975;292:344-7.

2. Bohan A, Peter JB. Polymyositis and dermatomyositis (second of tow parts). N Engl Med. 1975;292:403-7.

3. Lee CS, Chen TL, Tzen CY, et al. Idiopathic inflammatory myopathy with diffuse alveolar damage. Clin Rheumatol. 2002;21:391-6.

4. Fathi M, Dastmalchi M, Rasmussen E, et al. Interstitial lung disease, a common manifestation of newly diagnosed polymyositis and dermatomyositis. Ann Rheum Dis. 2004;63:297-301.

5. Chua F, Higton AM, Colebatch AN, et al. Idiopathic inflammatory myositis associated interstitial lung disease: ethnicity differences and lung function trends in a British cohort. Rheumatology (Oxford). 2012;51:1870-6.

6. Chen IJ, Jan $\mathrm{Wu} \mathrm{YJ,} \mathrm{Lin} \mathrm{CW,} \mathrm{et} \mathrm{al.} \mathrm{Interstitial} \mathrm{lung} \mathrm{disea-}$ se in polymyositis and dermatomyositis. Clin Rheumatol. 2009;28:639-46.

7. Hallowell RW, Danoff SK. Interstitial lung disease associated with the idiopathic inflammatory myiopathies and the antisynthetase syndrome: recent advances. Curr Opin Rheumatol. 2014;26:684-9. 
8. Bailey EE, Fiorentino DF. Amyopathic dermatomyositis: definitions, diagnosis, and management. Curr Rheumatol Rep. $2014 ; 16: 465$.

9. Galimberti F, Li Y, Fernandez AP. Clinically amyopathic dermatomyositis: clinical features, response to medications and malignancy-associated risk factors in a specific tertiary-carecentre cohort. Br J Dermatol. 2016;174(1):158-64.

10. Bendewald MJ, Wetter DA, Li X, Davis MDP. Incidence of dermatomyositis and clinically amyopathic dermatomyositis: a population-based study in Olmsted County, Minnesota. Arch Dermatol. 2010;146(1):26-30.

11. Cozzani E, Cinotti E, Felletti R, Pelucco D, Rebora A, Parodi A. Amyopathic dermatomyositis with lung involvement responsive to mycophenolate mofetil. Immunopharmacol Immunotoxicol. 2013;35(6):687-92.

12. Hirakata M, Suwa A, Nagai S, et al. Anti-KS: identification of autoantibodies to asparaginyl-transfer RNA synthetase associated with interstitial lung disease. J Immunol.1999; 162:2315-20.

13. Betteridge Z, Gunawardena H, North J, et al. Antisynthetase syndrome: a new autoantibody to phenylalanyl transfer RNA synthetase (anti-Zo) associated with polymyositis and interstitial pneumonia. Rheumatology (Oxford). 2007;46:1005-8.

14. Hamaguchi Y, Fujimoto M, Matsushita T, et al. Common and distinct clinical features in adult patients with anti-aminoacyltRNA synthetase antibodies: heterogeneity within the syndrome. PLoS One. 2013;8:e60442.

15. Hallowell RW, Ascherman DP, Danoff SK. Pulmonary manifestations of polymyositis/dermatomyositis. Semin Respir Crit Care Med. 2014;35:239-48.

16. Wilkes MR, Sereika SM, Fertig N, et al. Treatment of antisynthetase associated interstitial lung disease with tacrolimus. Arthritis Rheum. 2005;52:2439-46.

17. Cavagna L, Caporali R, Abdi-Ali L, et al. Cyclosporine in anti-Jo1-positive patients with corticosteroid-refractory interstitial lung disease. J Rheumatol. 2013;40:484-92.

18. Matsumura Y, Shindo Y, Linuma Y, Yamamoto M, Shirano M, Matsushima A, et al. Clinical characteristics of Pneumocystis pneumonia in non-HIV patients and prognostic factors including microbiological genotypes. BMC Infect Dis. 2011;11:76.

19. Chew LC, Maceda-Galang LM, Tan YK, Chalraborty B, Thumboo J. Pneumocystis jirovecii pneumonia in patients with autoimmune disease on high-dose glucocorticoid. J Clin Rheumatol. 2015;21:72-5.

20. Morris A, Norris KA. Colonization by Pneumocystis jirovecii and its role in disease. Clin Microbiol Rev. 2012;25:297-317.

21. Procop GW, Haddad S, Quinn J, Wilson ML, Henshaw NG, Reller LB, et al. Detection of Pneumocystis jirovecii in respiratory specimens by four staining methods. J Clin Microbiol. 2004;42:3333-5.

22. Karageorgopoulos DE, Qu JM, Korbila IP, Zhu YG, Vasileiou VA, Falagas ME. Accuracy of beta-D-glucan for the diagnosis of Pneumocystis jirovecii pneumonia: a meta-analysis. Clin Microbiol Infect. 2013;19(1):39-49.

23. Tasaka S, Hasegawa N, Kobayashi S, et al. Serum indicators for the diagnosis of pneumocystis pneumonia. Chest. 2007;131:1173.

24. Church D, Ambasta A, Wilmer A, et al. Development and validation of a Pneumocystis jirovecii real-time polymerase chain reaction assay for diagnosis of Penumocystis pneumonia. Can J Infect Dis Med Microbiol. 2015;26(5):263-7.

25. Krajicek BJ, Thomas CF, Limper AH. Pneumocystis pneumonia: current concepts in pathogenesis, diagnosis, and treatment. Clin Chest Med. 2009;30:265-78.

26. Thomas CJ, Limper A. Pneumocystis pneumonia. N Engl J Med. 2004;350:2487-98.

27. Mansharamani NG, Garland R, Delaney D, Koziel H. Management and outcome patterns for adult Pneumocystis carinii pneumonia, 1985 to 1995: comparison of HIV-associated cases to other immunocompromised states. Chest. 2000;118:704-11.

28. Enomoto T, Azuma A, Kohno A, Kaneko K, Saito H, Kametaka $\mathrm{M}$, et al. Differences in the clinical characteristics of Pneumocystis jirovecii pneumonia in immunocompromised patients with and without HIV infection. Respirology. 2010;15:126-31.

29. Wang XL, Wang XL, Wei W, An CL. Retrospective study of Pneumocystis pneumonia over half a century in mainland China. J Med Microbiol. 2011;60:631-8.

30. Fujii T, Nakamura T, Iwamoto A. Pneumocystis pneumonia in patients with HIV infection: clinical manifestations, laboratory findings, and radiological features. J Infect Chemother. 2007;13:1-7.

31. Sepkowitz KA. Opportunistic infections in patients with and patients without acquired immunodeficiency syndrome. Clin Infect Dis. 2002;34:1098-107.

32. Tasaka S, Tokuda H. Pneumocystis jirovecii pneumonia in nonHIV-infected patients in the era of novel immunosuppressive therapies. J Infect Chemother. 2012;18:793-806.

33. Tasaka S, Kobayashi S, Kamata H, Kimizuka Y, Fujiwara H, Funatsu Y, et al. Cytokine profiles of bronchoalveolar lavage fluid in patients with Pneumocystis pneumonia. Microbiol Immunol. 2010;54:425-33.

34. Yusuke Ainoda, Yuji Hirai, Takahiro Fujita, Noriko Isoda, Kyoichi Totsuka. Analysis of clinical features of non-HIV Pneumocystis jirovecii pneumonia. J Infect Chemother. 2012;18:722-8.

35. Huang L, Crothers K, Morris A, Groner G, Fox M, Turner JR, et al. Pneumocystis colonization in HIV-infected patients. J Eukaryot Microbiol. 2003;50(Suppl):616-7.

36. Ponce CA, Gallo M, Bustamante R, Vargas SL. Pneumocystis colonization is highly prevalent in the autopsied lungs of the general population. Clin Infect Dis. 2010;50:347-53. 
37. Suryaprasad A, Stone JH, When is it safe to stop Pneumocystis jirovecii pneumonia prophylaxis? Insights from three cases complicating autoinmune diseases. Arthritis Rheum. 2008;59:1034.

38. Centers for Disease C, Prevention. Prevention and control of seasonal influenza with vaccines. Recommendations of the Advisory Committee on Immunization Practices-United States, 2013-2014. MMWR Recomm Rep. 2013; 62(RR07):1-43.

39. Cohen A, McMorrow M, Walaza S, Cohen Ch, et al. Potential impact of co-infections and co-morbidities prevalent in Africa on influenza severity and frequency: a systematic review. Plos One. 2015;10(6):e0128580.

40. Brankston G, Gitterman L, Hirji Z, et al. Transmission of influenza A in human beings. Lancet Infect Dis. 2007;7:257.

41. Mubareka S, Lowen AC, Steel J et al. Transmission of influen- za virus via aerosols and fómites in the guinea pig model. $\mathrm{J}$ Infect Dis. 2009;199(6):858.

42. Memoli MJ, Athota R, Reed S, et al. The natural history of influenza infection in the severely immunocompromised vs. nonimmunocompromised hosts. Clin Infect Dis. 2014;58(2).

43. Chertow DS, Memoli MJ. Bacterial coinfection in influenza: a grand rounds review. JAMA. 2013;309930:275-82.

44. Chartrand C, Leeflang MM, Minion J, et al. Accuracy of rapid influenza diagnostic test: a meta-analysis. Ann Intern Med. 2012;156:500.

45. US Centers for Disease Control and Prevention. Guidance for clinicians on the use of RT-PCR and other molecular assays for diagnosis of influenza virus infection. Disponible: en http:/www.cdc.gov/flu/professionals/diagnosis/molecularassays.htm [Acceso 4 Apr 2012]. 